\title{
Returning to the roots. A Comment on the Paper "Alliance in Common Factor Land: A View through the Research Lens"
}

\author{
Antonello Colli ${ }^{1}$
}

It is an honor for me to comment on a paper by Adam Horvath, who is considered one of the most important therapeutic alliance researchers of our time.

In his interesting paper "Alliance in Common Factor Land: A View through the Research Lens," Horvath (2011) takes us through the critical aspects of therapeutic alliance research and the challenges that researchers still have to face. The author discusses several complex issues - from the historical background of the construct to the critical aspects of its measurement, and concludes with the proposal of a research agenda.

The key topic of Horvath's (2011) paper is the necessity for a better definition of therapeutic alliance construct, one that would (a) recognize the similarities and differences among the different kinds of therapeutic alliance definitions; and (b) differentiate the components of the therapeutic relationship. As Horvath reminds us in his paper, the problem of differentiation between therapeutic alliance and other components of the relationship originates from Greenson's (1965) tripartition of therapeutic relationship in transference, working alliance, and real relationship.

Some authors refute this tripartition and think that the psychotherapy relationship is the product only of patient's transference: There cannot exist a conflict-free part of the Ego. Other authors believe this tripartition is possible as well as useful. Last, some authors equate the alliance with the therapeutic relationship.

\footnotetext{
${ }^{1}$ University of Urbino, Italy.

E-mail: antonello.colli@uniurb.it
} 
If the distinction among the three elements of the therapeutic relationship - in terms of mutually exclusive categories - seems possible on a theoretical level, then from a clinical perspective, this differentiation appears more difficult, with the boundaries blurred among the constructs (Hatcher, 2009).

It is not useful or clinically meaningful to debate the elements of a therapeutic relationship in terms of mutually exclusive categories: transference or therapeutic alliance or real relationship (Hatcher, 2009). Conversely, it is more important to reflect on the way we view the psychotherapy relationship. Horvath (2009) suggested a possible solution to classifying relational constructs along a three-layered hierarchy: feelings, relational inferences, and relational processes (p. 276). Another possibility could be looking at psychotherapy relationship components as different levels of the relationship experience (Lingiardi \& Colli, 2010; Meissner, 2006; Modell, 1990). Every patient-therapist sentence - for example, "You do not love me" - can be interpreted concurrently as the expression at a first level of something of the reality: the patient and the therapist as persons; at a second level: the "I" and the "You" referencing the patient and the analyst; and, finally, at a third level: interpreted as the expression of transference, with the "I" and the "You" referring to figures in the patient's past.

The question from this point of view is: On what level - transference, therapeutic alliance, or real relationship - are the therapist and patient mainly working?

Hatcher suggests considering the three components of the relationship as different perspectives of observation. In this way "Anything that happens in the relationship can be evaluated from the alliance point of view, suggesting such questions such as: In what way [does] this behavior indicate the quality of the work in therapy? . . . Does this behavior promote or detract from the work?" (Hatcher, 2010, p. 22).

This way of conceptualizing and working on the relationship is in line with Horvath's (2011) proposal about the necessity to "discover and docu- 
ment more clearly the kind of interactive processes that most likely foster the alliance" (p. 131).

The investigation of how the patient and therapist construct the therapeutic alliance, to depict "the idiosyncratic interactional patterns that unfold between patient and therapist" (Charmann, 2004, p. 18), suggests promoting studies based on the evaluation of micro processes between patient and therapist (Colli \& Lingiardi, 2009).

Restarting from what the patient and therapist do during psychotherapy sessions could contribute in giving us "a clearer classification of the relationship constructs currently in use. . . [and] the recognition of both the similarities and the differences among the constructs currently labeled alliance" (Horvath, 2011, p. 132). As Horvath (2011) observed, the problem is also recognizing the differences among the therapeutic alliance definitions. These differences are more evident if we take into consideration that "less than $50 \%$ of the variance was shared among these most commonly used measures" (Horvath, 2011, p. 129). One possible explanation for this data, as Horvath proposes in his paper, could be that the most commonly used measures are based on different conceptualizations of the therapeutic alliance. Conversely, this data could be the result of some problematics in therapeutic alliance measures; for example, a critical aspect of therapeutic alliance measures - how clients and therapist "use" the Likert scale - could affect the interpretation of the low agreement of these measures. As observed by Jenkins and Dillman (1997), researchers who create questionnaires do not always know how respondents will answer them. This is also the case in therapeutic alliance. Despite using different instruments to assess the client-therapist alliance, authors of studies frequently comment that both clients and therapists tend to rate the alliance highly (i.e., Hilsenroth, Peters, \& Ackerman, 2004; Lingiardi, Filippucci, \& Baiocco, 2005; Tryon \& Kane, 1995). For example, Hatcher and Gillaspy found that clients tend not to use the lower 5 points of the 7-point Working Alliance Inventory (WAI) (Hatcher \& Gillaspy, 2006). Thus, clients used just the top 30\% of the rating points of the WAI when evaluating their alliance with therapists. An- 
other study of differences in the use of the Likert scale between patients and therapist showed that clients tend to use only the top $20 \%$ of rating points and therapists tend to use only the top $30 \%$ of rating points on alliance measures (Tyron, Blackwell, \& Hammel, 2008).

A further critical aspect that could affect the variance among these measures is represented by several biases in self-report measures. The evaluations of therapeutic alliance could be affected by the influence of other relational variables, including transference and countertransference, the therapist's theoretical preferences, or the influence of other variables related to the patient's level of functioning, such as reflective functioning capacity (Colli \& Lingiardi, 2009).

All critical aspects of therapeutic alliance construct seem to aggregate when we focus our attention on the construct of alliance ruptures and resolutions.

As Horvath (2011) noticed for therapeutic alliance (p. 126) as well as for therapeutic alliance ruptures and resolutions, we have a "Tower of Babel" effect. In fact, several terms have been used to describe this phenomenon: challenges (Harper, 1989a, 1989b), misunderstanding event (Rhodes, Hill, Thompson, \& Elliott, 1994), impasses (Hill, Nutt-Williams, Heaton, Thompson, \& Rhodes, 1996), alliance threats (Bennett, Parry, \& Ryle, 2006), transference-countertransference enactments (Safran \& Muran, 2006), and rupture interactions (Colli \& Lingiardi, 2009). At the same time, for therapeutic alliance ruptures and resolutions, we have a Tower of Babel problem in reverse: We use the same words but mean different things.

In his paper, Horvath (2011) observed that in the research literature on therapeutic alliance ruptures and resolutions, "The kind of data that is interpreted as evidence that a rupture has taken place varies significantly with the researcher's method of assessment" (p. 130) and that "at one end, almost any sign of momentary tension between therapist and client is assumed to signal some kind of rupture . Near the other end of the continuum, there are significant fluctuations in self-reported alliance between sessions as the criteria that trigger a rupture" (Horvath, 2011, p. 130). 
These differences in assessing therapeutic alliance ruptures and resolutions could reflect radical differences at a theoretical level. These theoretical differences can be summarized into two opposing positions: the totalistic/relational and the restricted/rational. From a totalistic/relational point of view, the therapeutic alliance is seen as "an ongoing process of intersubjective negotiation" (Safran \& Muran, 2000, p. 165). The object of this negotiation could change from author to author: For example, for Safran and Muran (2000), patients and therapists negotiate agency and relatedness needs. For other authors, patients and therapists negotiate about self and interactive regulation (Beebe \& Lachmann, 2002). From this view, the psychotherapy process can be conceptualized as a process of ruptures and resolutions of the syntonization between patient and therapist, a process that takes place at both conscious and unconscious levels (Lyons-Ruth, 1999). As a consequence, also momentary and subtle fluctuations in the collaboration level are considered relevant.

From a restricted/rational position, therapeutic alliance ruptures and resolutions are one of the elements of the psychotherapy process but do not represent the essence of the psychotherapy process. This perspective has a greater relevance for what the patient communicates rather than how the patient communicates. If we adopt a rational point of view, we could consider it a rupture or breakdown in the collaboration process if a patient does not agree with his or her therapist about a task of therapy (for example "I don't think it is important for me to speak about my childhood"). Conversely, if we adopt a relational point of view, the content of the communication (the disagreement) is less important than the way the patient communicates about the disagreement and negotiates it with the therapist.

In conclusion, I believe that the routes traced by Horvath (2011) indicate the necessity to return to the roots of conceptualizations and our clinical work. This return could permit us to partially mark and reflect about the boundaries of therapeutic alliance, reducing naïve assumptions and especially not transforming therapeutic alliance from an aspecific factor into an "umbrella" factor. 


\section{References}

Beebe, B., \& Lachmann, F. M. (2002). Infant Research and Adult Treatment: Coconstructing Interactions. Hillsdale, NJ: The Analytic Press.

Bennett, D., Parry, G., \& Ryle, A. (2006). Resolving threats to the therapeutic alliance in cognitive analytic therapy of borderline personality disorder: A task analysis. Psychology and Psychotherapy: Theory, Research and Practice, 79(3), 395-418.

Charman, D. (2004). (Ed.). Processes in Brief Psychodynamic Psychotherapy: Advancing Effective Practice. Hillsdale, NJ: Lawrence Erlbaum Associates.

Colli, A., \& Lingiardi, V. (2009). The Collaborative Interactions Scale: A new transcript-based method for the assessment of therapeutic alliance ruptures and resolutions in psychotherapy. Psychotherapy Research, 19(6), 718-734.

Greenson, R. R. (1965). The working alliance and the transference neuroses. Psychoanalytic Quarterly, 34, 155-181.

Harper, H. (1989a). Coding Guide I: Identification of confrontation challenges in exploratory therapy. (Unpublished manuscript.) University of Sheffield, Sheffield, UK.

Harper, H. (1989b). Coding Guide II: Identification and classification of therapist markers and withdrawal challenges. (Unpublished manuscript.) University of Sheffield, Sheffield, UK.

Hatcher, R. L. (2009). Considering the real relationship: Reaction to Gelso's "The real relationship in a postmodern world: Theoretical and empirical explorations." Psychotherapy Research, 19(3), 269-272.

Hatcher, R. L. (2010). Alliance theory and measurement. In C. Muran \& J. P. Barber (Eds.), The therapeutic alliance: An evidence-based guide to practice (pp. 7-28). New York, NY: Guilford Press.

Hatcher, R. L., \& Gillaspy, J. A. (2006). Development and validation of a revised short version of the Working Alliance Inventory. Psychotherapy Research, 16, 12-25.

Hill, C. E., Nutt-Williams, E., Heaton, K. J., Thompson, B. J., \& Rhodes, R. H. (1996). Therapist retrospective recall of impasses in long-term psychotherapy: A qualitative analysis. Journal of Counseling Psychology, 43, 207-217. 
Hilsenroth, M., Peters, E., \& Ackerman, S. (2004). The development of therapeutic alliance during psychological assessment: Patient and therapist perspectives across treatment. Journal of Personality Assessment, 83, 332-344.

Horvath, A. O. (2009). How real is the "real relationship"? Psychotherapy Research, 19(3), 273-277.

Horvath, A. O. (2011). Alliance in common factor land: A view through the research lens. Research in Psychotherapy. Psychopatology, Process and Outcome, 14(1), 121-135.

Horvath, A. O., \& Greenberg, L. S. (1989). The development and validation of the Working Alliance Inventory. Journal of Counseling Psychology, 36, 223-233.

Jenkins, C., \& Dillman, D. (1997). Towards a theory of self-administered questionnaire design. In L. E. Lyberg, P. Biemer, M. Collins, E. DeLeeuw, C. Dippo, N. Schwarz, \& D. Trewin (Eds.), Survey measurement and process quality (pp. 165-196). New York, NY: John Wiley \& Sons.

Lingiardi, V., \& Colli, A. (2010). L'alleanza terapeutica nelle psicoterapie psicodinamiche [The therapeutic alliance in psychodynamic therapies]. Psicobiettivo, 1, 28-53.

Lingiardi, V., Filippucci, L., \& Baiocco, R. (2005). Therapeutic alliance evaluation in personality disorders psychotherapy. Psychotherapy Research, 15(12), 45-53.

Lyons-Ruth, K. (1999). The two-person unconscious: Intersubjective dialogue, enactive relational representation and the emergence of new forms of relational organization. Psychoanalytic Inquiry, 19(4), 576-617.

Meissner, W. W. (2006). Finding and refinding the therapeutic alliance: On thinking and thirds. Journal of American Academy of Psychoanalysis and Dynamic Psychiatry, 34, 651-678.

Modell, A. H. (1990). Other times, other realities: Toward a theory of psychoanalytic treatment. Cambridge, MA: Harvard University Press.

Rhodes, R., Hill, C. E., Thompson, B. J., \& Elliott, R. (1994). Client retrospective recall of resolved and unresolved misunderstanding events. Journal of Counseling Psychology, 41, 473-483.

Safran, J. D., \& Muran, J. C. (2000). Negotiating the therapeutic alliance: A relational treatment guide. New York, NY: Guildford Press.

Safran, J. D., \& Muran, J. C. (2006). Has the concept of the therapeutic alliance outlived its usefulness? Psychotherapy: Theory, Research, Practice, Training, 43(3), 286-291. 
Stiles, W. B., Glick, M. J., Osatuke, K., Hardy, G. E., Shapiro, D. A., Agnew-Davies, R., . . Barkham, M. (2004). Patterns of alliance development and the rupturerepair hypothesis: Are productive relationships U-shaped or V-shaped? Journal of Counseling Psychology, 51(1), 81-92.

Tryon, G. S., \& Kane, A. S. (1995). Client involvement, working alliance, and type of therapy termination. Psychotherapy Research, 5, 189-198.

Tryon, G. S., Blackwell, S. C., \& Hammel, E. F. (2008). The magnitude of client and therapist working alliance ratings. Psychotherapy Theory, Research, Practice, Training, 45(4), 546-5 